\title{
Constancy of glucose and starch fermentations by two different human faecal microbial communities
}

\author{
G A WeAVER, J A KRAuse, T L Miller, AND M J WOLin
}

From the Department of Medicine, The Mary Imogene Bassett Hospital (affiliated with Columbia University), Cooperstown, New York and Wadsworth Center for Laboratories and Research, New York State Department of Health, Albany, New York, USA

SUMMARY The fermentation of glucose and corn starch by faecal suspensions from two subjects was examined over a three and a half year period. The substrate specificity and products of the faecal fermentations of each subject were relatively stable during this period and were significantly different between subjects. The major soluble end products of fermentation of glucose or starch were acetate, propionate, and butyrate. Hydrogen temporarily accumulated and was subsequently used in fermentations by both subjects. Hydrogen was used without methane production in fermentations of subject 1 , but was used for methane formation in fermentations of subject 2 . Although the rates of glucose fermentation were similar between both subjects; subject 1 produced a significantly greater molar ratio of propionate than did subject 2 . The rate of fermentation of starch by faecal suspensions from subject 1 was faster than that of subject 2 . The molar ratio of butyrate was greater for starch fermentations by subject 2 , while the molar ratio of propionate was greater with subject 1 . Significant differences were found between subjects in molar ratios and concentration of acetate and propionate and concentrations of butyrate in faeces.

The microbial community of the adult human colon ferments dietary components that escape host digestive processes. The major fermentation products are short chain volatile fatty acids (acetate, propionate, and butyrate) (SCFA), carbon dioxide, and methane and/or hydrogen. ${ }^{1}$ Major substrates for the fermentation are the plant cell wall carbohydrates, cellulose, hemicellulose, and pectin, and small molecular weight oligosaccharides - for example, stachyose, that are not hydrolysed by host enzymes. ${ }^{12}$ Dietary components that are incompletely digested by host enzymes and enter the colon - for example, starch and lactose, are also fermented. ${ }^{3-7}$ The fermentation is produced by a community of distinctly different species of anaerobic bacteria. Metabolic activities of individual species and interactions between the metabolic activities of the species accomplish the overall conversion of

Address for correspondence: G A Weaver, The Mary Imogene Bassett Hospital, Cooperstown, New York 13326, USA.

Received for publication 5 May 1988. substrates to the characteristic SCFA and gases of the colonic fermentation. ${ }^{1}$

The general features of the fermentation appear to be similar in all adults. ${ }^{1}$ There is, however, little information about the variability of the fermentation. Variability, which reflects qualitative and/or quantitative differences in the species that constitute the microbial community, might be manifested in several ways. The microbiota of individuals might differ in their capacity to ferment different substrates. An extreme example of this is the demonstration that the faecal microbial communities of about $20 \%$ of the human population examined fermented the highly crystalline cellulose present in filter paper whereas the microflora of all of the human population fermented the amorphous cellulose found in vegetables. ${ }^{8}$ The result implies differences in the kinds of species that digest cellulose. Products might vary between and within individuals. An extreme example is the production of methane by the microbial communities of some individuals and not by 19 
of a particular bacterial species that uses hydrogen to reduce carbon dioxide to methane. ${ }^{10}{ }^{11}$ Hydrogen is a major fermentation product of other species that cannot produce methane. ${ }^{1}$ The amounts of methane production and the concentrations of the bacteria that produce methane from hydrogen and carbon dioxide differ markedly between individuals but are stable within an individual. ${ }^{12}$ Because different species make different contributions to the production of the individual SCFA, variations of the proportions of acetate, propionate, and butyrate may occur. Examples of these variations in SCFA are known for the rumen fermentation which is very similar to the colonic fermentation. ${ }^{13}$ The possible occurrence of similar variations in colonic fermentations has, however, not been investigated.

The present study was initiated to examine the possibility that an individual adult produces a relatively constant fermentation over long periods of time. This would indicate the presence of a relatively stable microbial community. This question has not been investigated except for studies of methane formation. We examined the fermentation of two substrates, glucose and corn starch, by faecal suspensions of two subjects over a period of three and a half years to determine if substrate specificity and product formation remained constant for each subject. The microorganisms in the faecal suspensions were assumed to represent the colonic microbial community. The results presented in this report show that the substrate specificity and fermentation products of the fermentations of each subject and their faecal SCFA concentrations were relatively stable during the study period and were significantly different between subjects.

\section{Methods}

\section{SUBJECTS}

Two volunteers, selected because of their availability and willingness to contribute faecal samples, were studied frequently over a three and a half year period. Subject 1 was known to be breath methane negative and subject 2 was breath methane positive. In addition, subject 2 had diverticulosis. This study was initially reviewed and approved by the review board for human subjects of The Mary Imogene Bassett Hospital in July, 1981, with subsequent yearly approvals.

\section{ANAEROBIC PROCEDURES}

Stringent anaerobic conditions were maintained by use of the serum bottle modification of the Hungate technique. ${ }^{14}$ All gas mixes were certified standards or of ultra high purity $(99.99 \%)$, traces of $\mathrm{O}_{2}$ were removed by prior passage through a heated column containing copper filings. ${ }^{15}$

FAECAL SAMPLE PREPARATION

Faecal samples were collected and processed within three hours of voiding of the stool. Weighed amounts of faeces were placed in plastic bags and flushed with $80 \% \mathrm{~N}_{2}: 20 \% \mathrm{CO}_{2}\left(\mathrm{~N}_{2}: \mathrm{CO}_{2}\right)$, anaerobic dilution solution $^{16}$ was added to the sample, and the bag was sealed. The suspension was mixed by kneading until it was uniform in consistency. The contents of the bag were transferred to a serum bottle while flushing the headspace of the bottle with $\mathrm{N}_{2}: \mathrm{CO}_{2}$. The bottle was sealed and kept on ice until the suspension was used in experiments. The final suspension of faeces was $5 \%$ or $10 \%(\mathrm{w} / \mathrm{v})$. The time elapse from preparation of the suspension to addition of the suspension to experimental bottles was about 30 minutes.

\section{DRY WEIGHT DETERMINATIONS}

The gram dry weight (gdw) of duplicate portions of faecal samples $(5 \mathrm{~g}$ wet $)$ were determined as previously described. ${ }^{11}$

\section{FERMENTATIONS}

Fermentations were carried out in $20 \mathrm{ml}$ serum bottles. All additions to the bottles were made at $4^{\circ} \mathrm{C}$ while the bottles were flushed with $\mathrm{N}_{2}: \mathrm{CO}_{2}$. Duplicate serum bottles containing $5 \mathrm{ml}$ basal medium (Table 1 ) with $1 \%$ glucose, $1 \%$ corn starch or no added substrate were gassed with $\mathrm{N}_{2}: \mathrm{CO}_{2}$. Five millilitre of faecal suspension, prepared as described above, was added and the bottles were sealed.

For one hour incubations, the bottles were first placed in a $37^{\circ} \mathrm{C}$ water bath for five minutes and

Table 1 Composition of incubation medium*

\begin{tabular}{lc}
\hline Addition & Amount $/ 100 \mathrm{ml}$ \\
\hline $2 \cdot 5 \% \mathrm{KH}_{2} \mathrm{PO}_{4}(\mathrm{pH} \mathrm{7} \cdot 0)$ & $20 \mathrm{ml}$ \\
$2 \cdot 5 \% \mathrm{NaHCO}_{3}$ & $20 \mathrm{ml}$ \\
$1 \cdot 25 \%$ each cysteine $\mathrm{HCl}$ and $\mathrm{Na}_{2} \mathrm{~S} \cdot 9 \mathrm{H}_{2} \mathrm{O}$ & $6 \mathrm{ml}$ \\
Anaerobic dilution solution & $14 \mathrm{ml}$ \\
Substrate & $1 \mathrm{~g}$ \\
$\mathrm{H}_{2} \mathrm{O}$ & $39 \mathrm{ml}$ \\
\hline
\end{tabular}

*The medium is prepared under $80 \% \mathrm{~N}_{2}: 20 \% \mathrm{CO}_{2}$. The composition of anaerobic dilution solution is given in reference 16 . 
baseline incubations ( $T_{0}$ samples) were removed and heated in a boiling water bath for 10 minutes. For all other incubations, $T_{0}$ samples were taken directly from each bottle while the bottles were held at $4^{\circ} \mathrm{C}$. After removal of $T_{0}$ samples, bottles were placed on a rotator in a $37^{\circ} \mathrm{C}$ incubator. Incubation was terminated by heating the stoppered bottles for 10 minutes in a boiling water bath. The bottles were then equilibrated to room temperature before measurement of gas pressure and gas composition. The incubation mixtures were removed from each bottle, centrifuged at $2000 \times g$ for 10 minutes and the supernates were used for all analyses unless stated otherwise. Samples that were not analysed immediately were stored at $-20^{\circ} \mathrm{C}$ and thawed rapidly before subsequent measurements.

Rates of fermentation are expressed as total $\mu$ moles of product formed from substrate/unit time/ gram dry weight of faeces. Values obtained without added substrate (endogenous values) were subtracted from the values obtained with substrate. Twenty four hour time course fermentations (Figs 1-4) were not corrected for endogenous values.

\section{SHORT CHAIN FATTY ACID ANALYSIS}

Two different methods were used. The initial method was an ether extraction method. The latter method did not use ether extraction. Before changing to the latter method, both methods were applied to identical samples and gave identical results.

Ether extraction of SCFA was carried out according to the procedure outlined in the Supelco Inc Bulletin $748 \mathrm{Ge}$ as follows: Two millilitres of the supernatant were acidified to below pH 2 with $35 \mu \mathrm{l}$ $50 \% \mathrm{H}_{2} \mathrm{SO}_{4}$ and $10 \mu \mathrm{l} 5 \mathrm{mM}$ internal standard (2-ethylbutyric acid) was added. The samples were mixed by inversion and $1.0 \mathrm{ml}$ of ethyl ether was added. The tubes were gently mixed and briefly centrifuged to break up the emulsion. The aqueous

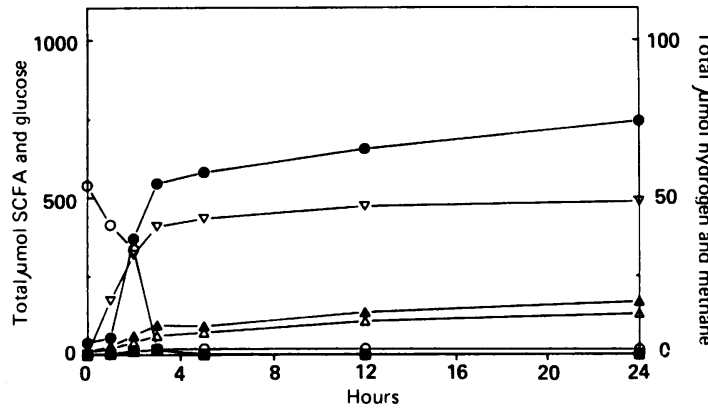

Fig. 2 Time course of glucose fermentation by subject 2. The experimental conditions are described in Methods. Symbols: O: glucose; O: acetate; $\triangle$ : propionate; $\boldsymbol{\Delta}$ : butyrate; $\square$ : hydrogen; $\nabla:$ methane.

phase was frozen and the ether layer was removed for analysis. A 1.0 $\mu \mathrm{l}$ sample of the ether extract was used for chromatographic injection. Samples were analysed using a Perkin Elmer gas chromatograph fitted with a flame ionisation detector and a $1.80 \mathrm{~m} \times$ $0.63 \mathrm{~cm}$ glass column packed with $15 \%$ SP $1220 / 1 \%$ $\mathrm{H}_{3} \mathrm{PO}_{4}$ on 100/120 Chromosorb W AW (Supelco, Inc). Short chain volatile fatty acid concentrations were determined with a Hewlett-Packard 3390A integrator using the internal standard method. Per cent recovery from SCFA spiked samples for each SCFA was: acetate $108 \%$, propionate $99 \%$, isobutyrate $96 \%$, butyrate $100 \%$, isovalerate $90 \%$, and valerate $92 \%$. Coefficients of variation for repeated determinations were less than $6 \%$.

Samples that were not ether extracted were acidified by adding $40 \mu \mathrm{l} 50 \%$ sulphuric acid to $4 \mathrm{ml}$ boiled fermentation suspension. After centrifugation, the supernatant was filtered through a $0.45 \mu \mathrm{m}$ filter. Trimethylacetic acid was added as an internal standard. One microlitre of the sample was used for chromatographic analysis with a Perkin Elmer gas

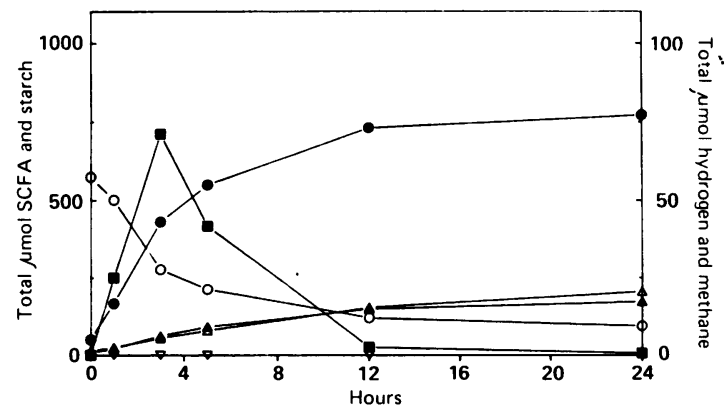

Fig. 3 Time course of corn starch (as glucose equivalents) fermentation by subject 1 . The experimental conditions are described in Methods. Symbols: О: corn starch; O: acetate; $\triangle$ : propionate; $\mathbf{\Delta}$ : butyrate; $\mathbf{Q}$ : hydrogen; $\nabla$ : methane. 


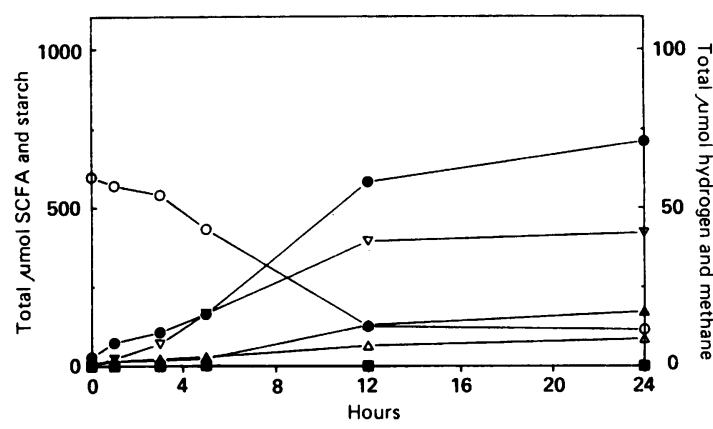

Fig. 4 Time course of corn starch (as glucose equivalents) fermentation by subject 2 . The experimental conditions are described in Methods. Symbols: O: corn starch; O: acetate; $\triangle$ : propionate; $\Delta$ : butyrate; $\square$ : hydrogen; $\nabla$ : methane.

chromatograph with a flame ionisation detector and a $1.80 \mathrm{~m} \times 0.63 \mathrm{~cm}$ glass column packed with $80 / 120$ Carbopack B-DA $/ 4 \%$ Carbowax $20 \mathrm{M}$ (Supelco, Inc Supelco Park, Bellefonte, PA 16823-0048). Per cent recovery of SCFA from spiked samples for each SCFA was: acetate $102 \%$, propionate $99 \%$, isobutyrate $98 \%$, butyrate $99 \%$, isovalerate $96 \%$ and valerate $96 \%$. Coefficients of variation for repeated determinations were less than $4 \%$.

\section{GAS MEASUREMENT}

Barometric pressure and temperature were recorded on experimental days and all determinations were corrected for changes in both. Headspace gas pressures in the serum bottles were measured using a mercury manometer fitted with $0.07 \mathrm{~cm}$ tubing and a $25 \mathrm{~g}$ needle to minimise the dead space. All calculations were corrected for the dead space volume of the system. Hydrogen and methane were determined by gas chromatography as previously described."

GLUCOSE AND STARCH DETERMINATIONS

Glucose and starch were determined by the anthrone method. ${ }^{17}$

\section{Results}

TIME COURSE OF FERMENTATIONS

Faecal suspensions of subjects 1 and 2 were incubated with glucose for 24 hours. The time course of glucose disappearance and the production of hydrogen and SCFA for subject 1 is shown in Figure 1. Production of acetate and hydrogen occurred at a rapid rate for approximately four hours. At that point, glucose was completely used, hydrogen production began to decrease and the rate of production of acetate sharply diminished. The rate of butyrate formation also decreased when the rate of acetate formation decreased. Propionate appeared to be produced at a relatively constant rate throughout the 24 hour incubation period. Only trace amounts of methane were detected. Results obtained with the suspension of subject 2 are shown in Figure 2. Production of acetate, butyrate, propionate, and methane occurred for about three hours, at which time the glucose was completely used. Little fermentation occurred thereafter. Essentially the same time patterns of substrate utilisation and product formation were obtained with suspensions of subjects 1 and 2, respectively, when the same experiments were done 12 months earlier than the experiments described in Figure 1 and 2. Only relatively little isobutyric, isovaleric and valeric

Table 2 Rates of fermentation of glucose or corn starch by faecal suspensions*

\begin{tabular}{|c|c|c|c|c|c|c|c|c|}
\hline \multirow[b]{2}{*}{ Substrate/time } & \multirow[b]{2}{*}{$n$} & \multicolumn{7}{|c|}{ umol/time/g dry weight $\dagger$} \\
\hline & & Substrate use & $\ddagger$ Hydrogen & Methane & Acetate & Propionate & Butyrate & Valeric \\
\hline $\begin{array}{l}\text { Glucose, } 1 \text { h: } \\
\text { Subject } 1 \\
\text { Subject } 2\end{array}$ & $\begin{array}{l}11 \\
11\end{array}$ & $\begin{array}{r}1018(253) \\
816(550)\end{array}$ & $\begin{array}{l}326(169) \\
507(1206)\end{array}$ & $\begin{array}{c}0 \S \\
14(23) \S\end{array}$ & $\begin{array}{l}807(376) \S \\
433(273) \S\end{array}$ & $\begin{array}{l}25(38) \\
46(39)\end{array}$ & $\begin{array}{c}134(117) \\
62(77)\end{array}$ & $\begin{array}{l}3(32) \\
2(2)\end{array}$ \\
\hline $\begin{array}{l}\text { Corn starch, } 1 \text { h: } \\
\text { Subject } 1 \\
\text { Subject } 2\end{array}$ & $\begin{array}{l}6 \\
6\end{array}$ & $\begin{array}{r}1127(383) \S \\
486(159) \S\end{array}$ & $\begin{array}{c}303(269) \S \\
6(6) \S\end{array}$ & $\begin{array}{l}0 \S \\
5(3) \S\end{array}$ & $\begin{array}{l}689(342) \S \\
188(248) \S\end{array}$ & $\begin{array}{r}51(70) \\
0(20)\end{array}$ & $\begin{array}{l}103(147) \S \\
-13(42) \S\end{array}$ & $\begin{array}{l}1(40) \\
1(5)\end{array}$ \\
\hline $\begin{array}{l}\text { Corn starch, } 6 \text { h: } \\
\text { Subject } 1 \\
\text { Subject } 2\end{array}$ & $\begin{array}{l}3 \\
3\end{array}$ & $\begin{array}{l}2059(169) \\
1283(933)\end{array}$ & $\begin{array}{c}186(170) \\
5(6)\end{array}$ & $\begin{array}{c}0 \S \\
45(9) \S\end{array}$ & $\begin{array}{l}2092(250) \S \\
469(102) \S\end{array}$ & $\begin{array}{c}362(101) \S \\
42(21) \S\end{array}$ & $\begin{array}{r}538(20) \S \\
80(52) \S\end{array}$ & $\begin{array}{r}-3(9) \S \\
20(8) \S\end{array}$ \\
\hline
\end{tabular}

*Samples were obtained over a two year period for one hour experiments and over a two month period for six hour experiments.

† Means (SD). Only trace amounts $(<2 \mu \mathrm{mol} / \mathrm{gdw} / \mathrm{time})$ of isobutyrate and isovalerate were produced.

$\ddagger$ In one hour experiments glucose disappearance was determined in nine and starch disappearance in four incubations.

$\S$ Means of the two subjects that were significantly different by a two-tailed $t$ test. $p$ Values were:

one hour glucose: acetate, 0.01 ; methane, 0.01

one hour corn starch: hydrogen, 0.02 ; methane, 0.005 ; starch disappearance, 0.02 ; acetate, 0.01; butyrate, 0.04

six hour corn starch: methane, 0.002; acetate, $0 \cdot 001$; propionate 0.007 ; butyrate, 0.0007 ; valerate, 0.03 . 
acids were formed in these and other incubations described in this report.

The time course of starch fermentation by faecal suspensions of subject 1 is shown in Figure 3 . The rate of starch disappearance appeared to be slower than the rate of glucose disappearance by suspensions of the same subject (Fig. 1). Hydrogen was produced more slowly and disappeared more rapidly when starch was the substrate (Fig. 3) than when glucose was the substrate. Production of acetate, propionate, and butyrate from starch (Fig. 3) was similar to that from glucose (Fig. 1). Starch fermentation by subject 2 is depicted in Figure 4. The rate of starch disappearance was much slower than the rate of glucose disappearance by suspensions from the same subject (Fig. 2) and production of SCFA and methane was much slower with starch (Fig. 4) than with glucose (Fig. 2).

\section{RATES OF FERMENTATION}

Although the rates of glucose fermentation by suspensions of the two subjects were similar (Figs. 1 and 3), the rates of starch fermentation differed significantly (Figs. 2 and 4). Rate differences were examined in more detail by analysing one-hour fermentations of glucose and starch with faecal suspensions obtained over a two year period. In addition, six hour starch fermentations with three separate faecal suspensions from each subject, obtained over a two month period, were examined. The results (Table 2) showed that much greater amounts of acetate, propionate and butyrate were produced from starch by suspensions from subject 1 during the six hour period than were produced by suspensions from subject 2 . There was higher production of valerate, a minor product, by the starch fermentations of subject 2 . Results of one hour starch incubations of different faecal suspensions from each subject confirmed the differences in rates of fermentation of starch between the subjects (Table 2). There also was a significant difference in the rates of acetate production from glucose between the two subjects (Table 2). This may be because of a lag in the production of acetate by subject 2 (Fig. 2). Subject 2 also produced significant amounts of methane in all incubations while subject 1 produced none or only trace amounts.

\section{PROPORTIONS OF SCFA}

The amounts of SCFA produced and the proportions of individual SCFA in the total SCFA mixture after complete fermentation of $100 \mathrm{mg}$ of substrate by suspensions from each subject were examined. The results (Table 3) showed that the amounts and proportions of propionate produced from glucose by subject 1 were significantly higher than that produced by subject 2 when glucose was the substrate. With starch, production and proportions of acetate and propionate were higher for subject 1 and the amount and proportion of valerate was higher for subject 2 . The proportion of butyrate was higher in subject 2 with starch as substrate, but the amounts produced/ $100 \mathrm{mg}$ of starch fermented were not significantly different than that produced by subject 1 .

FAECAL SCFA

The concentrations of SCFA and proportions of acetic, propionic, and butyric acids in faeces from the two subjects obtained over a three year period are shown in Table 4. The total amounts of faecal SCFA were significantly higher for subject 1 (Table 4 ). The molar ratio of propionate to total SCFA was significantly higher for subject 1 , whereas the molar ratio of acetate and isovalerate to total SCFA, as well as the dry weight of faeces, were significantly higher for subject 2 .

\section{Discussion}

The fermentation patterns of the faecal suspensions

Table 324 hour glucose and corn starch fermentation products and per cent molar ratios

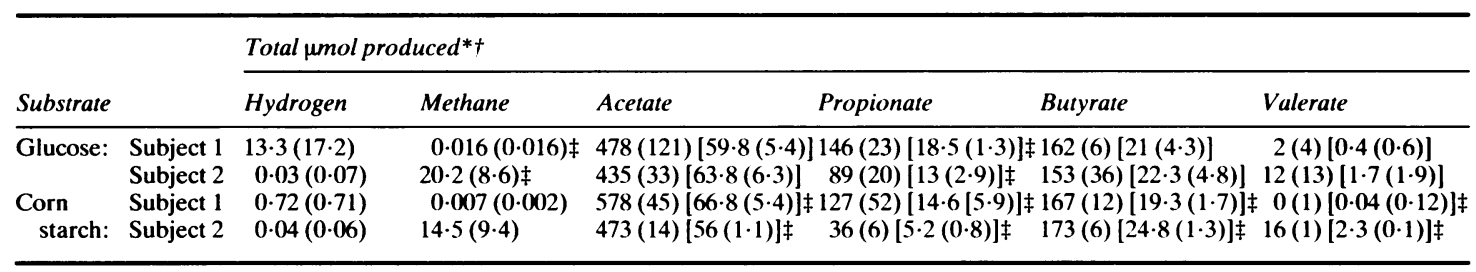

*Means of $\mu$ moles of products formed $/ 100 \mathrm{mg}$ substrate ( $555 \mu \mathrm{mol}$ glucose equivalents) (SD). Only trace amounts $(<2 \mu \mathrm{mol})$ of isobutyrate and isovalerate were produced. Three determinations for each subject and substrate (glucose over 10-month period, corn starch over 3month period).

†Numbers in square brackets are the means of per cent molar ratios of products (SD).

¥Means of the two subjects that were significantly different by a two-tailed $t$ test. $p$ Values were: glucose fermentation, concentrations: methane, 0.02 ; propionate, 0.03 ; ratios: propionate, $0 \cdot 04$; corn starch fermentations, concentrations: acetate, $0 \cdot 02$; propionate, $0 \cdot 04$ : valerate, $0 \cdot 001$; ratios: propionate, $0 \cdot 05$; butyrate, $0 \cdot 01$; valerate, $0 \cdot 001$. 
Table 4 SCFA concentrations and per cent molar ratios in faeces from 1984 through 1987

\begin{tabular}{|c|c|c|c|c|c|c|c|c|}
\hline \multirow[b]{2}{*}{ Subject $¥$} & \multirow[b]{2}{*}{$g d w$ faeces } & \multicolumn{7}{|c|}{$\mu \mathrm{mol} / g d w$ faeces*t } \\
\hline & & $\begin{array}{l}\text { Total } \\
\text { SCFA }\end{array}$ & Acetate & Propionate & Isobutyrate & Butyrate & Isovalerate & Valerate \\
\hline 1 & $0 \cdot 24(0.07) \S$ & $492(339) \S$ & $\begin{array}{l}289(168) \S \\
{[60(5 \cdot 2)] \S}\end{array}$ & $\begin{array}{l}86(62) \S \\
{[17 \cdot 6(4 \cdot 0)] \S}\end{array}$ & $\begin{array}{l}10(19) \\
{[1 \cdot 8(1 \cdot 3)] \S}\end{array}$ & $\begin{array}{l}81(68) \S \\
{[15 \cdot 5(4 \cdot 7)]}\end{array}$ & $\begin{array}{l}12(18) \\
{[2 \cdot 5(1.8)] \S}\end{array}$ & $\begin{array}{l}14(23) \\
{[2 \cdot 5(1 \cdot 6)]}\end{array}$ \\
\hline 2 & $0.33(0.05) \S$ & $258(120) \S$ & $\begin{array}{l}165(83) \S \\
{[63 \cdot 5(4 \cdot 3)] \S}\end{array}$ & $\begin{array}{l}32(13) \S \\
{[12 \cdot 5(2 \cdot 1)] \S}\end{array}$ & $\begin{array}{l}9(7) \\
{[3 \cdot 2(1.2)] \S}\end{array}$ & $\begin{array}{l}37(19) \S \\
{[14 \cdot 2(3 \cdot 1)]}\end{array}$ & $\begin{array}{l}9(4) \\
{[3 \cdot 8(1.5)] \S}\end{array}$ & $\begin{array}{l}7(5) \\
{[2 \cdot 8(1.4)]}\end{array}$ \\
\hline
\end{tabular}

*Means $\mu \mathrm{mol} / \mathrm{gram}$ dry weight (gdw) of faeces (SD).

†Numbers in square brackets are means of per cent molar ratios of products (SD).

$\ddagger$ Twenty one determinations for each subject.

$\$$ Means of the two subjects were significantly different by a two-tailed $t$ test. p Values were: gdw 0.0002; total SCFA, 0.005; acetate, 0.005; propionate, 0.0006; butyrate, $0 \cdot 006$. Per cent molar ratios: acetate, $0 \cdot 024$; propionate, $0 \cdot 0001$; isobutyrate, $0 \cdot 002$; isovalerate, $0 \cdot 012$.

of the two subjects were sufficiently constant over a period of time to allow comparisons of the activities of the microbial flora of the subjects. The flora of subject 1 clearly has a greater capacity to ferment starch than the flora of subject 2 . Studies in recent years have shown differences in malabsorption of starch depending upon the form of starch ${ }^{18} \mathrm{~A}$ recent study showed that normal subjects malabsorb more potato starch than did subjects with adenomatous polyps. ${ }^{6}$ The differences in rates of starch fermentation by faecal suspensions found in the present study may be a reflection of differences in malabsorption by the two subjects. Subject 1 may malabsorb more starch than subject 2 and therefore have a microbial community that is better adapted to ferment starch.

In addition to rate differences in substrate fermentation, the studies also showed differences between the two subjects in the amounts and proportions of acids produced. Subject 1 produced higher amounts and proportions of propionate with both glucose and starch. It is interesting to note that the pattern of high proportions of propionate of subject 1 hold for the SCFA distributions in faeces as well as in the in vitro fermentation system. In fact, if the ratios of acetate: propionate:butyrate in faeces and after in vitro incubation are compared, they are very similar. They are 63:19:18 in faeces and 61:19:21 after 24 hour incubations with glucose and 66:15:19 after 24 hour incubations with starch. Subject 1 , in addition to having a flora with greater capacity for fermenting starch, also has a flora with greater capacity for producing propionate from either starch or glucose.

Similar comparisons of the faecal ratios with in vitro ratios for subject 2 show wider differences. Acetate:propionate:butyrate is 70:14:16, 64:13:22, and 70:5:25: for faeces, in vitro glucose, and in vitro starch fermentations, respectively. A possible explanation is that subject 2 also had higher faecal dry weights and lower concentrations of SCFA (either on a dry or wet basis) than did subject 1 .
Perhaps absorption or metabolism of SCFA might lead to in vitro versus in vivo differences.

Subject 1 suspensions produced hydrogen rapidly from glucose and starch. After net hydrogen production ceased, hydrogen was used. Methane, which is produced by the reduction of carbon dioxide by hydrogen, was produced in only trace amounts by suspensions of subject 1 . Experiments in press ${ }^{14}$ have shown the use of hydrogen to reduce carbon dioxide to acetate by faecal suspensions that do not produce significant amounts of methane.

Because the microbial community of the large bowel is composed of a large number of different genera and species, an enormous effort is necessary to investigate quantitative differences in the concentrations of individual species between subjects or within a subject as a function of diet, age, environment, or other variables. For example, a difference in the production of 2 and 41 of methane per day between two individuals is a large difference in terms of accumulation and removal of gas in the host but may result from only a two-fold difference in the concentrations of the methane producing bacteria responsible for production of the gas. Detection of a two-fold difference in the concentration of bacteria for example, between $1 \times 10^{10}$ and $2 \times 10^{10}$ requires a technique that will selectively enumerate the methane producers and accurate methods of enumeration with replicates and statistical analysis to substantiate that the difference is real. Differences of microbial activities, however - for example, the rate of starch disappearance, are easily measured and provide a means of comparing the capacity for the activity between individuals or within an individual.

The results of the study show that relatively stable differences in the microbial community activities of different individuals can be detected by examining the rates of fermentation of different substrates and the arrays of fermentation products. The approaches described in this report can be used to examine 
differences within and between individuals in relation to the effects of diet, age, environment, disease, and other variables on the microbial fermentation in the colon. These comparisons can also be the starting point for investigations of the microbiological differences that cause the differences in colonic fermentation. If the hypothesis that differences in the capacity to ferment different substrates is related to differences in malabsorption, the studies of fermentation may prove a useful adjunct to other methods of investigating malabsorption.

This study was supported in part by the Steven C Clark Research Fund of The Mary Imogene Bassett Hospital and grant AI20244 from the National Institutes of Health. The authors thank Drs Theodore Peters, Jr, and Roberta Reed for helpful comments during the course of this study.

\section{References}

1 Wolin MJ, Miller TL. Carbohydrate fermentation. In: Hentges DJ, ed. Human intestinal microflora in health and disease. New York: Academic Press, 1983: 147-65.

2 Salyers AA, Leedle JAZ. Carbohydrate metabolism in the human colon. In: Hentges DJ, ed. Human intestinal microflora in health and disease. New York: Academic Press, 1983: 129-46.

3 Anderson IH, Levine AS, Levitt MD. Incomplete absorption of the carbohydrate in all-purpose wheat flour. N Engl J Med 1981; 304: 891-2.

4 Stephen AM, Haddad AC, Phillips SF. Passage of carbohydrate into the colon. Direct measurements in humans. Gastroenterology 1983; 85: 589-95.

5 Englyst HN, Cummings JH. Digestion of the polysaccharides of some cereal foods in the human small intestine. Am J Clin Nutr 1985; 42: 778-87.

6 Thornton JR, Dryden A, Kelleher J, Losowsky MS. Super-efficient starch absorption. A risk factor for colonic neoplasia. Dig Dis Sci 1987; 32: 1088-91.
7 Bond JH, Levitt MD. Quantitative measurement of lactose malabsorption. Gastroenterology 1976; 70: 1058-62.

8 Ehle FR, Robertson JB, Van Soest, PJ. Influence of dietary fibres on fermentation in the human large intestine. J Nutr 1982; 112: 158-66.

9 Bond JH, Engel RF, Levitt MD. Factors influencing pulmonary methane excretion in man. An indirect method of studying the in situ metabolism of the methane producing colonic bacteria. J Exp Med 1971; 133: $572-88$.

10 Miller TL, Wolin MJ. Methanogens in human and animal intestinal tracts. System Appl Microbiol 1986; 7: 223-9.

11 Weaver GA, Krause JA, Miller TL, Wolin MJ. Incidence of methanogenic bacteria in a sigmoidoscopy population: an association of methanogenic bacteria and diverticulosis. Gut 1986; 27: 698-704.

12 Miller TL, Wolin MJ. Stability of Methanobrevibacter smithii populations in the microbial flora excreted from the human large bowel. Appl Environ Microbiol 1983; 45: 317-8.

13 Wolin MJ. Fermentation in the rumen and human large intestine. Science 1981; 213: 1463-8.

14 Miller TL, Wolin MJ. A serum bottle modification of the Hungate technique for culturing obligate anaerobes. Appl Microbiol 1974; 27 : 985-7.

15 Latham MJ, Sharpe ME. The isolation of anaerobic organisms from the bovine rumen. In: Shapton DA, Board RG, eds. Isolation of anaerobes. New York, London: Academic Press, 1971: 133-47.

16 Bryant MP, Burkey LA. Cultural methods and some characteristics of the more numerous groups of bacteria in the bovine rumen. J Dairy Sci 1953; 36: 205-17.

17 Frederick JV, Silverman L. Determination of starch and cellulose with anthrone. Anal Chem 1949; 21: 950-3.

18 Englyst $\mathrm{HN}$, Cummings JH. Digestion of polysaccharides of potato in the small intestine of man. Am J Clin Nutr 1987; 45: 423-31.

19 Lajoie SF, Bank S, Miller TL, Wolin MJ. Acetate production from hydrogen and ${ }^{131} \mathrm{C}$-carbon dioxide by the microflora of human feces. Appl Environ Microbiol 1988; 54: (In press). 